\title{
Transtornos Alimentares: uma perspectiva analítico-comportamental
}

\section{Eating Disorders: a behavioral analysis perspective}

\author{
Antonio Maia Olsen do Vale \\ Universidade Federal do Ceará \\ Especialista em Saúde Mental e Mestre em Saúde Pública \\ Liana Rosa Elias \\ Universidade Federal do Ceará \\ Especialista em Neuropsicologia
}

\section{Resumo}

O presente artigo apresenta uma compreensão analítico-comportamental dos "Transtornos Alimentares", especificamente a "Anorexia Nervosa" e a "Bulimia Nervosa”. As práticas bulímicas e anoréticas foram caracterizadas a partir dos três níveis de seleção por consequências. No nível filogenético, foi discutida a evolução do homem e sua relação com os quadros clínicos. Na ontogênese, a relação operante com o alimento foi apresentada, apontando-se possibilidades funcionais em diversas situações clínicas. Por último, discutiu-se a participação da indústria da estética na cultura capitalista; a qual vende a ideia de que o corpo magro remove contingências aversivas e pode ser comprado ou conquistado, como um objeto de consumo dissociado do sujeito que se comporta e de sua história. As práticas alimentares purgativas e restritivas são um problema de saúde pública, no qual o analista do comportamento pode intervir a partir da clínica, sem negligenciar a necessidade de uma compreensão dos processos micro e macro culturais envolvidos.

Palavras-chave: análise do comportamento; transtornos alimentares; anorexia nervosa; bulimia nervosa. 


\section{Abstract}

This article presents a Behavioral Analysis comprehension of the "eating disorders", specifically the "Anorexia Nervosa" and "Bulimia Nervosa". Anorexic and bulimic practices were characterized in the three levels of selection by consequences. At the phylogenetic level, was discussed the evolution of man and its relationship with clinical features. In the ontogenesis, the operant relationship with the food was presented, pointing functional possibilities in various clinical situations. Finally, was discussed the aesthetic industry involvement in the capitalist culture, which sells the idea that a thin body removes aversive contingencies and can be bought or conquered, as an object for consumption dissociated from the individual who behaves and his history. The purging and restrictive feeding practices are a public health problem, in which the behavior analyst can intervene from the clinic, without neglecting the need for an understanding of the micro and macro cultural processes involved.

Keywords: behavior analysis; eating disorders; anorexia nervosa; bulimia nervosa.

O presente artigo se propõe a apresentar didaticamente uma compreensão dos chamados "Transtornos Alimentares", e mais especificamente da "Anorexia Nervosa" e da "Bulimia Nervosa" (OMS, 1993), em uma perspectiva analítico-comportamental. A utilização dos termos psiquiátricos não ocorreu com o propósito de criar um manual de classificação ou análise, mas sim possibilitar que profissionais e alunos tenham como localizar este artigo como sendo uma proposta analítico-comportamental para compreensão desta temática.

Analistas do Comportamento frequentemente debatem sobre o uso de classificações psiquiátricas para a realização de suas análises e intervenções (Araújo \& Medeiros, 2003; Scoz, 2001; Banaco, 2001; Vermes \& Zamignani, 2002; Zamignani, 2000; Zamignani \& Banaco, 2005; Banaco, Zamignani \& Meyer, 2010). Banaco, Zamignani \& Meyer (2010) e Araújo $\&$ Medeiros (2003), apontam que o modelo médico e analítico-comportamental se embasam em pressupostos epistemológicos distintos nas suas propostas a respeito do diagnóstico clínico. Enquanto a psiquiatria se embasa nos critérios topográficos e estatísticos, a Análise do Comportamento (AC) privilegia critérios como funcionalidade, análise idiográfica do comportamento e o modelo contextualista e externalista de leitura das relações entre o objeto analisado e o ambiente.

Aiello (2002) e Vale (2002) apontam que o uso de classificações psiquiátricas por analistas do comportamento pode ter as seguintes funções:

a) Facilitar a comunicação interdisciplinar com psiquiatras e outros profissionais da área da saúde.

b) Realizar estudos epidemiológicos de populações específicas que possam fornecer dados para uma melhor compressão de fatores demográficos e socioculturais onde uma queixa clínica ocorre. Nestes, ocorre a utilização do diagnóstico psiquiátrico como referência para demarcar a população a ser investigada.

c) Agrupar estudos de caso com a mesma temática, proporcionando uma revisão da literatura.

d) Ter referências sobre pesquisas que investigam a base biológica de alguns quadros clínicos. 
e) Pesquisas transculturais.

f) Especificar a área de discussão acadêmica na literatura ou em eventos como palestras, cursos, seminários, etc., que envolvam a presença de profissionais da saúde e áreas afins.

Por adotar o modelo causal de seleção por consequências e rejeitar o mecanicismo (Andery, 1997; Chiesa, 2006), a Análise do Comportamento não busca explicar o comportamento como sendo o sintoma (efeito) de algum processo metafísico interno (causa). O comportamento é analisado como tendo valor em si próprio, pela função que ocupa nas relações contingenciais (Chiesa, 2006; Meyer, 2008). A queixa clínica não será compreendida como sintoma de uma causa, mas sim uma ação do cliente que é executada por ter uma funcionalidade na vida dele. As questões que o cliente apresenta podem se apresentar também como uma ausência de repertório comportamental, como a falta de habilidades ou demais condições para lidar com questões relevantes. A clínica analítico-comportamental busca identificar quais as funções que os comportamentos envolvidos naquela queixa têm na vida cotidiana do cliente e como esta funcionalidade foi historicamente construída (Delitti, 2001; Guilhardi, 2002). Realizar diagnóstico com base na identificação de "sintomas", com a finalidade de identificar uma entidade ou estruturas psicopatológicas metafísicas, que supostamente são a causa desse "sintoma", não é a proposta da Terapia Analítico-Comportamental. Duas pessoas com o mesmo diagnóstico, segundo a CID-10, apesar de apresentarem formas de agir topograficamente semelhantes (os mesmos "sintomas"), provavelmente serão tão diferentes em suas histórias de vida e na funcionalidade de suas ações que apenas o diagnóstico da CID-10 é insuficiente para a compreensão e investigação analítico-comportamental das queixas em suas vidas.
Os comportamentos humanos classificados como "normais" ou "patológicos" pela comunidade psiquiátrica, ou pelo senso-comum, seguem ambos as mesmas leis e princípios (Skinner, 1953). O foco da análise de orientação behaviorista radical está no comportamento e sua história de instalação e manutenção.

\section{A categoria transtornos alimentares}

Os chamados transtornos do comportamento alimentar englobam a Anorexia Nervosa (AN), a Bulimia Nervosa (BN), o Transtorno de Compulsão Alimentar Periódica (TCAP) e, dependendo da classificação utilizada, o transtorno alimentar não especificado (Kaplan et al., 1997; OMS, 1993; APA, 1995). Em comum, estas categorias estão relacionadas a respostas como: preocupação excessiva com o estado atual e/ ou um possível aumento da forma e do peso corporal; desejo de emagrecer; alterações na imagem corporal (discrepância entre a forma do corpo e a maneira como ele é descrito verbalmente); utilização de práticas danosas para controle de peso (uso de jejuns e dietas restritivas, vômitos, laxantes, etc.); busca exagerada pelo emagrecimento; culpa ao se alimentar, entre outros (Cordás, 1993; Vale, 2002).

A população feminina jovem, de 12 a 28 anos, é a mais atingida por este problema, numa proporção que chega a 20 casos em mulheres para cada caso em homens (Cordás, 1995). Por causa desta diferença na prevalência entre os gêneros, os transtornos alimentares são considerados pela literatura como um problema eminentemente feminino. Isto repercute no discurso dos artigos, que, em sua maioria, referem-se à população do estudo sempre no gênero feminino (Vale, 2002). Seguindo esta linha, o presente artigo discutirá a problemática em questão especificamente no público feminino. 
A palavra "anorexia" é de origem grega, significa falta de apetite (Cordás, 1993). Mas a categoria de respostas "anorexia nervosa" não se caracteriza necessariamente por uma falta de apetite, assim como acontece na anorexia em outros quadros clínicos como tuberculose e verminoses, mas sim pela recusa da alimentação e pela busca de um domínio sobre a fome e o corpo (Goldbloom \& Garfinkel, 1992). Através de um rígido autocontrole a cliente consegue efetivamente perder peso, mesmo que em alguns casos ocorram momentos de hiperfagia; este é um dos componentes centrais da categoria Anorexia Nervosa (AN). O repertório restritivo neste quadro pode ser bem diversificado e pouco sensível às consequências danosas decorrentes. É comum encontrar clientes que investem muito do seu tempo na elaboração e execução de estratégias para controle restritivo do peso, em detrimento de outras atividades que possibilitariam uma maior diversidade de fontes de reforçamento. Com o prosseguimento deste processo, o sucesso na restrição calórica pode se tornar um dos poucos reforçadores disponíveis na vida da cliente. A anoréxica pode se avaliar pela opinião do outro e atribuir os seus fracassos ao seu peso (Heller, 2002).

O começo deste quadro se dá, na maioria das vezes, com uma queda no peso, geralmente resultante de uma doença, tratamento médico ou dieta auto-induzida (Moschetta \& Cordioli, 1985). Durante a avaliação clínica é importante tentar identificar possíveis reforçadores (positivos e/ou negativos) desta primeira queda significativa de peso. Este processo vem acompanhado frequentemente de uma divergência entre a descrição verbal do tamanho e das formas do seu corpo e possíveis aferições antropométricas. Esta divergência é chamada na literatura psiquiátrica de alteração da Imagem Corporal (IC) (Cordás, 1993). Neste caso, mesmo que a cliente esteja claramente em grave estado de desnutrição, ela qualifica verbalmente sua forma corporal como "gorda". Durante a adolescência a relação com a forma do corpo é um fator crítico, pois as mudanças na puberdade impõem à adolescente uma adaptação de um corpo infantil para um corpo maduro com todas as características sexuais secundárias realçadas (Fleitlich, 1997). A maneira como ocorreu o preparo da recém adolescente para lidar como o novo corpo pode motivar a busca pelas práticas danosas de controle de peso e do corpo.

Outra característica para avaliar o impacto da restrição alimentar é o cálculo do Índice de Massa Corporal (IMC). Este índice foi criado pelo médico Quetelet. Seu cálculo é feito pela fórmula $(\mathrm{IMC}=$ peso $(\mathrm{kg}) / \mathrm{al}-$ tura (m)2), ou seja, o peso em quilos dividido pela altura em metros ao quadrado (OPAS, 2003). Segundo a OMS (1993), para que uma pessoa seja considerada anoréxica, o seu IMC teria que ser 17,5 ou menor. Existe um problema na utilização deste índice que deve ser levado em consideração: ele não faz distinção entre massa magra (músculos, ossos, água, etc.) e massa gorda (tecido adiposo), pois o cálculo mede a corpulência e não a adiposidade (Acuna e Cruz, 2004). Mesmo com este problema, o IMC, devido à sua praticidade, rapidez de resultado e simplicidade, ainda é um dos principais critérios para a avaliação da gravidade do quadro clínico (Anjos, 1992).

A palavra "bulimia", também tem origem grega, é uma derivação de duas palavras, "bous" que significa "boi” e, "limos" que significa "fome". Reunidas significam, na sua etimologia, uma fome bovina (Cordás, 1993). Uma das principais características da categoria bulimia nervosa, assim como na anorexia nervosa, são as tentativas de obter o corpo magro para ter acesso aos reforçadores. A diferença entre as duas categorias é que, na bulimia nervosa, mesmo que ocasionalmente ocorram tentativas de restrição alimentar 
bem sucedidas, estas, na maioria das situações falham. Os episódios bulímicos configuram-se como um consumo exagerado de grandes quantidades de alimento, com uma posterior tentativa de retirar esta comida do corpo através de diversos métodos (Cenci, Peres \& Vasconcelos, 2009). A purgação pode ocorrer através de qualquer prática que promova (de forma imaginária ou não) uma eliminação do alimento ingerido, tais como: vômitos, exercícios em excesso, fumo, uso de anorexígenos, chás, vinagre, laxantes, diuréticos, bebidas alcoólicas, etc. Durante este episódio bulímico a quantidade de calorias ingeridas geralmente varia entre 1.200 e 4.500 calorias (Claudino e Borges, 2002), podendo, inclusive, exceder este valor. Aquelas que apresentam estes episódios geralmente o descrevem como uma necessidade descontrolada de se "empanturrar" e depois sentir alívio (Cordás et al., 1998). Assim como na anorexia nervosa, também pode ocorrer a divergência entre descrição do corpo e a forma física do corpo. O início do quadro frequentemente ocorre nos últimos anos da adolescência até os 40 anos ou mais (Cordás, 1993). Casos de bulimia nervosa antes dos 12 anos são raros (Appolinário \& Claudino, 2000). Não é incomum a alternância entre fases "bulímicas" e fases "anoréticas" ao longo da história das clientes (Vale, 2002).

Em resumo, a anorexia nervosa (AN) engloba um efetivo repertório de autocontrole restritivo da ingestão de alimentos, o que pode levar a um peso abaixo do recomendado pela OMS. A bulimia nervosa (BN) engloba um pouco efetivo repertório de restrição alimentar, acompanhado de episódios de excessos de ingestão alimentar, que geralmente antecedem tentativas de privação alimentar ou purgação.

As duas categorias envolvem uma complexa interação, ainda não inteiramente compreendida ou expe- rimentalmente estudada, entre fatores filogenéticos (história da espécie), ontogenéticos (história do indivíduo) e socioculturais (Morgan, Vecchiatti e Negrão, 2002; Meyer, 2008; Cordás, 1993).

\section{Caracterização nos três níveis de seleção por consequências}

Segundo Skinner (1957, p.1), "os homens agem sobre o mundo e o modificam e, por sua vez, são modificados pelas consequências de sua ação". O termo comportamento nomeia a relação entre ações do organismo e o ambiente (Starling, 2000). Quando uma pessoa age, ela possibilita transformações nela e no que a cerca, ou seja, ocasiona consequências. Estas determinam probabilisticamente a frequência e a função de ações semelhantes em futuros contextos semelhantes.

O ser humano nasce com um aparato biológico que o permite ser sensível a certos tipos de consequências e a aprender (de forma não-verbal e posteriormente de forma verbal), que uma determinada ação pode ter uma determinada consequência, dado um contexto específico. Desta forma a ação passa a ter uma função para o sujeito que a realiza, e a ocorrer em função de determinadas contingências (Chiesa, 2006). Ao passar por experiências ao longo de sua história, a ação de uma pessoa passa a ser mais provável de ocorrer quando pode ser seguida de consequências relevantes para a mesma (Skinner, 1974).

No modelo causal de seleção por consequências proposto por Skinner $(1953,1981)$, a ocorrência da ação não pode ser explicada por uma causa que a provoca (modelo mecânico), mas sim pelas relações de contingência (dependência) entre os eventos antecedentes, a própria ação e as consequências que a sucedem (Meyer, 2003). A configuração entre estes três termos 
especifica a probabilidade do sujeito agir de uma determinada forma, em um determinado contexto.

Andery (1997) aponta, partindo de Skinner (1981), que a Análise do Comportamento compreende o comportamento humano como sendo possibilitado por três processos históricos: a história da espécie (filogenia), a história do indivíduo (ontogenia) e a história das práticas coletivas (cultura). Especialmente no ser humano, quase todos os comportamentos podem ser caracterizados como apresentando elementos que perpassam estes três níveis. O estudo de um dos níveis frequentemente exige a identificação do entrelaçamento com elementos dos outros níveis de análise. Neste artigo, a divisão do texto nos três níveis tem uma finalidade didática, pois não há uma hierarquização a priori entre a importância de cada um destes no processo estudado. A complexidade etiológica das classes de ações Anorexia e Bulimia Nervosa requisita sua caracterização nos três níveis para não cair em um reducionismo.

\subsection{A filogenia e a categoria transtornos alimentares:}

O comportamento alimentar integra o repertório de atividades necessárias à sobrevivência de qualquer espécie. Todo animal vivo necessita de alimento para o crescimento e manutenção de seus tecidos, e este é obtido através do comportamento alimentar. Conhecendo a história da nossa espécie, é possível inferir que o ambiente era adverso, com pouca disponibilidade de alimentos e períodos de escassez dos mesmos. Nesse ínterim, os indivíduos com mecanismos regulatórios eficazes no armazenamento de reservas energéticas sobreviveram (Netto, 2002). Ao estudar a fisiologia do comportamento alimentar, através da análise dos mecanismos de retroalimentação, fica evidente que há muitas defesas contra a subnutrição, e poucos mecanismos de regulação eficazes no evento de supernutrição (Kuppferman \& Schwartz, 1995).

Os seres humanos, em decorrência da seleção natural, já nascem com um aparato biológico sensível a certos tipos de alimentos. Assim, a comida, na história evolutiva da espécie humana, ganhou um papel reforçador incondicionado. Ou seja, todos os indivíduos da espécie humana nascem sensíveis ao alimento como reforçador. Esta sensibilidade biológica está relacionada também à eliciação de respondentes de prazer ao se ingerir o alimento (Netto, 2002). A sensibilidade ao alimento se caracteriza nas sensações diferenciadas entre alimentos diferenciados, como, por exemplo, sentir prazer ao ingerir carboidrato e sentir enjoo ao comer alimentos estragados. Os alimentos ricos em carboidratos, gorduras e açucares, por facilmente serem transformados em energia, foram úteis para a sobrevivência na evolução humana. Foram selecionadas na evolução da espécie aquelas variações de seres humanos que eram mais sensíveis a esses três tipos de alimentos. Este processo se manifesta no quanto eles são capazes de eliciar respondentes de prazer e entorpecimento. $\mathrm{O}$ potencial de reforço de certos grupos de alimentos, promovido durante a seleção natural, participa da explicação de por que dificilmente na clínica alguém irá relatar um episódio de compulsão alimentar com verduras em detrimento de alimentos hipercalóricos.

A ingestão de comida pode eliciar respondentes, considerados "prazerosos", incompatíveis com aqueles eliciados por eventos aversivos. Episódios de hiperfagia estão relacionados à liberação de opióides endógenos (Meyer, 2008). Assim, a cliente pode utilizar-se da comida como uma estratégia de controle emocional, mais especificamente para fugir do contato com emoções aversivas. 
Alguns comportamentos característicos dos chamados TA (Transtornos Alimentares) são decorrentes da privação alimentar; principalmente quando os mecanismos de regulação da homeostase entram em ação, na tentativa de lutar contra a desnutrição. Morgan et al. (2002) indicam que alterações em vias noradreninérgicas e da serotonina, presentes em clientes diagnosticadas com os quadros de $\mathrm{AN}$ e $\mathrm{BN}$, podem exercer papel predisponente em queixas clínicas relatadas pelas clientes como: humor alterado, forte controle de impulso, pensamentos obsessivos e alteração nos mecanismos de regulação da fome e saciedade. É provável que as anormalidades no sistema noradreninérgico sejam em decorrência dos períodos de jejuns e dietas aos quais essas clientes se submetem (Jimerson, 1992). A literatura aponta que a probabilidade de ocorrer um episódio de compulsão alimentar e pensamentos obsessivos sobre comida é bem maior quando existe uma restrição alimentar (Morgan et. al., 2002). Na BN, existe uma clara preferência por alimentos altamente calóricos, marcadamente carboidratos, durante o episódio de compulsão alimentar. Tal comportamento pode estar relacionado a uma alteração na produção da saciedade, mais especificamente a uma atividade deficiente no circuito serotoninérgico destas clientes (Morgan et al. 2002). A ânsia por carboidrato e o episódio de compulsão alimentar podem funcionar como estratégias de defesa para regularizar a homeostase e superar a desnutrição (Wurtman, 1987).

Outras consequências decorrentes da restrição alimentar são as alterações nos níveis de HLC (hormônio liberador de corticotrofina), NPY (neuropeptídeo Y) e VPA (vasopressina), que contribuem para o aparecimento da amenorreia de origem hipotalâmica e perda dos caracteres sexuais secundários. Estas alterações no aparato biológico necessário para a realização dos comportamentos de excitação sexual implicam em queixas de ausência de interesse sexual e pelo aparecimento de alterações do humor (Appolinário, 1998). A perda dos caracteres sexuais secundários em decorrência da restrição alimentar, em alguns casos de AN, pode adquirir função de reforço negativo. Por exemplo: o contato sexual, ao longo da história de uma cliente, pode ter se tornado aversivo em decorrência de uma educação sexual coercitiva por parte da família, ou episódios de abuso sexual, delineando-se um contexto em que as estratégias que impeçam o contato com situações sexuais sejam reforçadas negativamente. Outra situação seria a de uma pré-adolescente que, para não perder os reforçadores da vida infantil, restringe sua alimentação para não desenvolver o corpo com características femininas adultas.

Existe um mito de que as anoréxicas controlam perfeitamente os respondentes da classe "fome". Os dados experimentais invalidam esta afirmação. Por exemplo: se alguém está privado de comida, provavelmente a visão de um determinado alimento ou o cheiro deste é suficiente para eliciar a salivação. Esta operação, chamada de condicionamento reflexo (Millenson, 1967), acontece também com pacientes que relatam não se interessarem por comida. Broberg e Bernstein ${ }^{1}$ (apud Carlson, 2002 p.419) realizaram um experimento no qual ofereciam um bolinho com cobertura de açúcar e canela, quente e apetitoso, para um grupo de jovens anoréxicas e a um grupo de jovens magras (não anoréxicas). Eles disseram que elas poderiam comê-los se desejassem. Após 10 minutos, os experimentadores tiraram amostras de sangue e analisaram o conteúdo de insulina. Constataram que ambos os grupos apresentaram um aumento no nível de insulina. Surpreendentemente, o au- 
mento foi mais elevado nas anoréxicas. Como esperado, as não anoréxicas comeram o bolinho, e as anoréxicas não o fizeram. Nesta situação o relato das anoréticas não descreveu adequadamente as ações respondentes.

Sobre a prática excessiva de exercícios, estudos com animais não-humanos sugerem que o aumento da atividade física pode resultar do jejum. Os ratos que são privados de alimento gastam mais tempo correndo em uma roda de atividades, mesmo que isso signifique uma perda de peso mais rápida (Routtenberg, 1968). O relato clínico das anoréxicas aponta o sucesso na restrição alimentar prolongada como eliciador de sensações agradáveis e de potência. Estes dois dados são coerentes com um raciocínio que siga a lógica de operação da seleção natural, pois, na ausência prolongada de comida, seria importante para a sobrevivência da espécie que os indivíduos continuassem procurando novas fontes de alimento, mesmo que isso implique em mais gasto de energia. Existem relatos de pesquisas que apontam redução da sensação de fome naqueles que praticam exercícios físicos continuadamente (Carlson, 2002). A atividade física em excesso também elicia relaxamento, reduzindo a ansiedade (Fortes, 2006), além de ser um momento onde a cliente pode fugir de eventos aversivos públicos e privados da sua vida cotidiana ao se concentrar na realização do exercício.

A análise do $1^{\circ}$ nível de seleção é primordial para o entendimento dos comportamentos respondentes na categoria TA. O levantamento da literatura sugere que boa parte das complicações clínicas dos TA ocorrem em função da privação alimentar. Esta informação, levada ao contexto clínico, implica que uma mudança no quadro comportamental também depende de uma diminuição da restrição alimentar.

\subsection{A ontogenia e a categoria transtornos alimentares}

$\mathrm{Na}$ ontogênese, o foco de análise é o processo de seleção (pelas consequências), das repostas individuais (Andery, 1997). Enquanto a filogenia do comportamento alimentar esclarece relações entre o alimento e os respondentes, a ontogenia (segundo nível de seleção) das práticas alimentares estuda o alimento na sua relação com o comportamento operante, estabelecendo com este, relações de contingência.

A construção da relação entre o sujeito e o alimento se inicia nos primeiros momentos de vida. Neste processo várias possibilidades podem implicar na formação de práticas da categoria TA.

Frequentemente, os momentos em que uma criança é reforçada com alimento são acompanhados também de outros reforçadores, tais como atenção social, afeto dos pais, interação com estes, etc. Caso ocorra um pareamento, o alimento, além de já ser um reforçador incondicionado em decorrência da filogenia, passa a poder eliciar respondentes de bem-estar semelhantes aos eliciados por reforçadores sociais. Se a comida tiver também uma similaridade funcional com o reforçador social ou afetivo, ela poderá ser um substituto do afeto e da atenção social. Green \& Freed (1993) relatam que a substituição de reforçadores é um fenômeno importante para a compreensão de fenômenos clínicos na terapia comportamental. No campo dos Transtornos Alimentares é fundamental tentar identificar esta possibilidade. Pois, em situações de privação afetiva, a comida poderia ocupar o espaço de reforçadores sociais quando estes não estão disponíveis por alguma razão, como em situações de: ausência de habilidades sociais, supressão dos comportamentos sociais por controle coercitivo dos pais ou do grupo, etc. 
Um caso ilustrativo da situação descrita acima seria o de uma criança que passou por este condicionamento e que, ao entrar na adolescência, teve as regras para interação social ensinadas pelos pais. Estes pais, com receio "dos perigos do mundo", impediram esta adolescente de ingressar plenamente nas atividades sociais típicas da idade. Esta adolescente encontra na comida um substituto para o reforçamento social que perdeu ao entrar em outra etapa da vida. Claro que a comida não tem o exato efeito emocional das interações sociais, então é preciso uma significativa quantidade (forte intensidade) para que ocorra uma significativa eliciação de respondentes (forte magnitude) como prática compensatória. Como a comida está sendo ingerida numa quantidade acima do necessário para dar conta das necessidades nutricionais ocorrerá um ganho de peso. A mídia de consumo coloca frequentemente o corpo magro como meio para obter reforçadores como aceitação e sucesso social. Sendo assim, o corpo acima do peso (não considerado ideal pelo grupo social dela) seria, para a garota deste exemplo, mais um impeditivo para a sua realização social. Configura-se aqui a criação de uma operação estabelecedora que torna o corpo magro um efetivo reforçador, um meio para resolver a dificuldade de inserção no grupo sem precisar alterar relações familiares ou modo de vida dela própria. Para perder peso a adolescente pode começar a elaborar práticas que possam rapidamente resolver o problema do ganho de peso sem ter que perder a comida como fonte de prazer, tais como: vomitar, praticar atividades físicas em excesso, usar anorexígenos, etc.

Neste tipo de situação a comida possui vários papéis contraditórios. Tanto ela é aquilo que alivia (desfoca temporariamente dos respondentes da solidão, por exemplo) e elicia prazer, como também é aquilo que aumenta o peso e implica em senti- mentos de vergonha e culpa. O relato desta relação paradoxal com a comida é comum na clínica. A avaliação funcional deste caso poderia focar o atendimento para: a relação com a família e a dinâmica desta, o desenvolvimento de habilidades sociais, a ampliação de fontes de reforçamento social, entre outros (Heller, 2002).

No decorrer de sua história de vida, a cliente pode ter aprendido que o seu adoecimento é aversivo para os pais. Esta pode acabar provocando o adoecimento através da restrição alimentar como uma forma de exercer contracontrole diante do controle aversivo dos pais. Em outro extremo, o adoecer de desnutrição pode mobilizar a atenção de pessoas significativas para a paciente, ou mobilizá-los para liberarem outros reforçadores.

Outro exemplo da relação entre a cliente e a família na constituição do quadro clínico ocorre quando um possível ganho de peso de uma filha é aversivo não para ela, mas para a sua mãe. Esta pode privar a filha de certos alimentos e exercer um forte controle na sua conduta alimentar, além de ensinar regras que relacionam o ganho de peso ao fracasso e outras consequências aversivas (isolamento social, perda de afeto, desqualificação na sociedade, etc.). A privação de alimento torna mais provável que esta filha faça episódios de hiperfagia, provavelmente escondidos da mãe ou de outros. A hiperfagia pode levar ao ganho de peso, e, para se esquivar das consequências aversivas decorrentes deste, ela pode utilizar-se de práticas purgativas.

A relação com a comida é construída ao longo da história de vida, mas devem existir contingências de reforçamento atuais mantendo essa resposta em alta frequência no repertório da mesma. Como no seguin- 
te exemplo: uma adolescente com déficit no repertório de habilidades sociais e poucas amizades, após emagrecer, chama atenção de colegas de classe que começam a aceitá-la no grupo por sua aparência. A mesma consegue mobilizar atenção social neste grupo (reforço social) através de práticas restritivas para controle de peso (respostas), ou seja, com o corpo magro. Fica clara a contingência estabelecida entre "ficar magra (ação) - atenção social (consequência)". De posse dessas informações é possível levantar hipóteses sobre outras respostas que também possam gerar essa mesma consequência (atenção social). Daí o investimento no desenvolvimento de repertórios de habilidades sociais como uma possível estratégia clínica para esta situação (Heller, 2002). Com o progresso da terapia espera-se, nestes casos, que o novo repertório de habilidades sociais possa ocupar de forma mais positivamente reforçadora o espaço na vida da cliente, antes ocupado pelas consequências das práticas hiperfágicas e restritivas.

Outro ponto relevante nos quadros clínicos dos TA, especialmente nas que praticam a restrição de forma efetiva, é a recusa ao tratamento. As clientes relatam que as práticas anoréxicas não são um problema que ameace sua vida, muitas vezes citando sua busca pela magreza como um estilo de vida ou uma busca pela felicidade. É comum encontrar no relato de terapeutas casos de adolescentes que vêm encaminhadas para a clínica por familiares ou profissionais de saúde, e não por uma demanda da própria cliente. Também é comum estas clientes (por acharem que as práticas anoréticas e bulímicas não são danosas) trazerem como queixa clínica outros aspectos do seu cotidiano, como problemas com os pais ou dificuldades em estabelecer vínculos afetivos e sociais, dificuldades de concentração, dentre outros. São nestes temas que o terapeuta analítico-comportamental deve inicialmen- te focar para promover a adesão ao atendimento. Caso a cliente avalie que a terapia vai "engordá-la", a possibilidade de evasão do tratamento se torna alta. No caso das que realizam práticas bulímicas, podem ser trazidas queixas em torno da tentativa de desenvolver ou melhorar o repertório de autocontrole, para evitarem os episódios de alimentação em grande quantidade. Ou seja, a cliente pode estar procurando a terapia para diminuir a ingestão alimentar e assim não ganhar peso. Neste caso os mandos dentro da sessão podem ser semelhantes a estes: "Procurei a terapia para não comer compulsivamente", "Como faço para não comer tanto? Estou precisando aumentar o meu autocontrole", "Eu queria parar de comer tudo isso! Eu queria parar de comer". Nestes casos a situação é muito delicada. Pois existe um conflito entre as exigências da cliente e a postura ética do terapeuta. Será necessário um diálogo sobre o papel da terapia. $\mathrm{O}$ compromisso com a manutenção da vida da cliente é o norteador das ações do terapeuta, e isso deve ser claramente colocado para a cliente.

No caso de uma cliente que apresente condições de se submeter ao atendimento clínico, deve-se também colocar como foco de trabalho a análise da resistência às mudanças (Guilhardi, 2002). As regras das clientes acerca do tratamento podem ser apresentar como esta: "se eu permitir o tratamento, então eles me engordarão". O ambiente clínico, assim como a figura do terapeuta, deve evitar sinalizar controle aversivo para as clientes. O terapeuta deve ter cuidado ao explicar a proposta da terapia, fazendo-o de forma clara e falando abertamente que a terapia não é para fazê-la "ficar gorda". Mas que, dependendo do estado nutricional, o papel do terapeuta é pró-vida então ele apoiará medidas mais interventivas da equipe de profissionais que a atende, como por exemplo, a hospitalização em casos de risco para a vida da cliente. 
A atuação do terapeuta, através do impacto de suas características pessoais e de sua interação sobre os comportamentos do cliente, é um fator primordial para a adesão do cliente à terapia (Delitti, 2005). Através do fortalecimento da relação terapêutica é possível iniciar um trabalho que permita a sensibilização para as consequências do seu quadro clínico e formar uma parceria com a cliente para o conhecimento das contingências presentes na sua vida, propiciando um ambiente para as intervenções.

Estratégias como vomitar, comer compulsivamente e realizar atividades físicas em excesso exigem concentração, o que as torna boas estratégias para disfocar de sensações e pensamentos aversivos. Deaver et al. (2003) propuseram que o comer compulsivo poderia ser reforçado negativamente ao aliviar momentaneamente a pessoa de afetos aversivos. Heatherton e Baumeister (1991) afirmaram que os episódios de hiperfagia são uma forma de fuga do contato consigo mesmo e com emoções aversivas. Paxton \& Diggens (1997) afirmaram que tanto a restrição alimentar como o comer muito, apesar de topograficamente diferentes, podem se apresentar como uma forma de evitação ou fuga de estimulações aversivas. Diversos estudos apontam que experiências aversivas como abuso sexual, separações, mudanças, doenças, perdas, entre outros, são fatores de risco para a ocorrência de transtornos alimentares (Morgan et al., 2002; Paxton, 1998; Fiates \& Salles, 2001). Fugir pode se apresentar como uma ação para lidar com situações como estas, quando o sujeito não tem condições ou repertório para lidar de forma resolutiva com elas.

\subsection{A cultura e as práticas anoréticas e bulímicas}

No terceiro nível de seleção pelas consequências pode-se estudar como as práticas de uma cultura, jun- tamente com os dois primeiros níveis de seleção, participam da construção dos comportamentos relacionados às queixas centrais trazidas nos quadros clínicos dos TA.

Os transtornos alimentares são mostrados nas pesquisas epidemiológicas como quadros relativamente modernos e predominantemente ocidentais (Nunes et al., 1998). A aparência física mostra-se como um elemento fundamental nas relações sociais da cultura ocidental (Ribeiro et al., 2006). Pesquisadores vêm estudando a evolução do padrão de beleza feminino nas últimas décadas. Garner e Garfinkel (1980) compararam medidas de peso e forma corporal de modelos de capas de revistas masculinas e participantes de concursos de beleza ao longo de vinte anos (1959 - 1978). Demonstraram que houve uma progressiva mudança nos padrões de beleza de uma figura do tipo violão em direção a uma figura marcadamente mais magra, de um tipo mais andrógeno. Os dois autores verificaram ainda um significativo aumento de artigos sobre dietas para emagrecimento, publicados em seis revistas femininas ao longo do mesmo período. Durante as últimas décadas a massa corpórea das mulheres expostas na mídia vem diminuindo, coincidindo com um aumento na prevalência de TA na população feminina (Stice et al., 1994).

A indústria da moda exibe modelos cada vez mais magras nas passarelas e catálogos. Dezenas de revistas divulgando dietas restritivas e os mais diversos métodos de emagrecimento inundam as bancas. Livros com receitas emagrecedoras mágicas viram best-sellers por semanas. Os outdoors apresentam propagandas que verbalmente estabelecem uma relação de contingência entre emagrecimento e reforçadores positivos variados. Por exemplo: uma campanha de uma indústria de shakes para emagrecimento apresentada 
no final da década de 90 em outdoors onde se lia "Felicidade é entrar num vestido P" ou "A melhor maneira de conquistar um homem é pelo estômago: o seu estômago". As fotos das modelos e atrizes, lindas e com corpos esculturais são digitalizadas, afastando cada vez mais a mulher comum das "musas photoshopizadas2".

A mídia voltada para a promoção do consumo é um meio rápido e eficaz de se disseminar mandos e regras. Existe uma expressiva divulgação de fórmulas de rápido emagrecimento, de mensagens explícitas ou implícitas da magreza como sinônimo de reforçadores generalizados, tais como status social, competência, e atratividade sexual.

A busca pela magreza como forma de se enquadrar nos padrões estabelecidos de beleza é algo que perpassa todas as camadas sociais. Vale (2002) realizou um levantamento epidemiológico sobre práticas típicas dos TA em uma amostra representativa $(n=652)$ das adolescentes estudantes no município de Fortaleza (CE). O medo de engordar foi relatado pela maioria destas adolescentes (62\%), e não foi possível afirmar que houve diferença significativa na distribuição deste relato entre as alunas de colégios públicos e particulares $(\mathrm{p}>0,05)$.

A preocupação das mulheres com o peso corporal não tem origem apenas numa questão de saúde ou de uma preocupação com os males do excesso de gordura. $\mathrm{Na}$ verdade, a mesma possui uma forte imposição mercadológica. A indústria da magreza gera lucro para os mais diversos grupos econômicos (empresas de produtos alimentares, indústria têxtil, médicos, indústria de cosméticos, mídia, etc.), que se sustentam através da constante busca das mulheres por um corpo que seja socialmente considerado belo (Vale, 2002). A “in- dústria da magreza", através da propaganda, fornece estímulos discriminativos verbais que explicitam contingências onde "se comprar o produto $X(\mathrm{R})$ então você terá o corpo magro e assim a felicidade (S+)". Regras como essa sinalizam consequências reforçadoras que vão além da utilidade específica do produto. Estas regras poderiam ser descritas no formato: "se você consumir a sopa diet $\mathrm{X}(\mathrm{R})$ então terá o corpo magro (S+) e também será aceita $(\mathrm{S}+)$ e bem sucedida $(\mathrm{S}+)$ ".

Na sociedade de consumo, a magreza é apresentada como uma mercadoria ilusoriamente acessível a todos, independentemente das contingências filogenéticas e ontogenéticas. A magreza é vendida como um produto relacionado ao autocontrole, à competência e à atratividade sexual (Morgan et al., 2002).

Tratar o corpo como um objeto de consumo, que pode ser arbitrariamente moldado com dietas e cirurgias, sem levar em consideração o sujeito que se comporta, pode enganosamente criar a concepção de que o primeiro é dissociado do segundo. Configura-se neste caso uma falsa dualidade "sujeito X corpo", semelhante ao clássico dualismo "mente X corpo". Essa nova dicotomia se apresenta na dificuldade discriminativa de algumas clientes em tratar a si e ao seu corpo como uno, e assim, relatá-lo como um todo em relação aos demais eventos em sua vida. Na clínica, uma cliente pode verbalizar o corpo como algo dissociado de si em frases como: "esse corpo não combina comigo", "se meu corpo fosse magro eu não me sentiria tão mal" ou "esse corpo não reflete quem eu sou". O corpo pode ganhar o papel de responsável pelas contingências aversivas às quais a cliente está submetida. A indústria da beleza confirma este raciocínio declarando que a mudança no corpo promove mudanças nas contingências aversivas e nos respondentes emocionais. 
Ao lidarmos com regras e auto-regras, temos que salientar que o comportamento não é causado por estas. Se assim o fosse, entraríamos numa lógica mecânica onde, por exemplo, uma propaganda (causa) provocaria necessariamente a prática de restrição alimentar (efeito). As regras são um estímulo discriminativo verbal, que especificam probabilidades de ocorrência de um evento em relação a outro (se... então...). O que altera a probabilidade de ocorrência da resposta de seguir uma regra são as consequências produzidas pela mesma em situações passadas (Skinner, 1974; Baum, 2005). A atenção social recebida após o seguimento de uma regra como "se eu emagrecer minha vida será melhor" é algo que pode fortalecer a ação de seguir a mesma. A validação social cria um status de verdade para esta regra, mesmo que a relação especificada verbalmente entre a ação e a consequência não seja de dependência direta.

A magreza como padrão estético dominante é um dos fatores responsáveis por outro fenômeno da categoria Transtornos do Comportamento Alimentar (TCA): a distorção da Imagem Corporal (IC). Este comportamento não depende apenas da forma física do corpo. Ele é construído também pelas contingências sociais de reforçamento. A IC é uma categoria que envolve comportamento perceptivo exteroceptivo e comportamento verbal descritivo. A comunidade é responsável pelo estabelecimento do reforço para o comportamento de relacionar forma física e a adjetivação da mesma. São os pais e as pessoas próximas à criança que nos seus primeiros anos de vida disponibilizam reforço para quando na presença de um obeso, seguindo um modelo apresentado, ela fala "gordo". Ao aprender a qualificar a forma do outro a criança também irá aprender a se qualificar fisicamente. Desde pequenas as crianças aprendem a discriminar quais características estéticas a comunidade valoriza e quais rejeita
(Castilho, 2004; Ribeiro et al., 2006). A comunidade verbal é responsável pela forma como aprendemos a tatear (Baum, 2005), incluindo o tatear verbalmente o corpo e as repercussões disso.

Para várias pessoas o critério para saber se está gordo ou magro não é a forma do corpo em si, mas sim a avaliação do outro, ou a comparação com parâmetros socialmente determinados; o autoconhecimento é de origem social (Andery, 1997). Falas como a seguinte ilustram este fenômeno: "quando alguém fala que estou mais cheinha me sinto mais gorda ainda".

O comportamento de qualificar o corpo depende do reforçamento diferencial estabelecido socialmente ao longo da história de vida. A indústria da estética é um grupo que atualmente, na cultura ocidental, tem poder de estabelecer os critérios para o reforçamento da correspondência entre o comportamento verbal de tato e a forma do corpo. Esta indústria não está preocupada em reforçar uma correspondência saudável entre a maneira de perceber o corpo e a forma deste. Pois, caso isso ocorresse, o mercado consumidor dos seus produtos diminuiria vertiginosamente. É necessário que as pessoas estejam insatisfeitas com sua aparência e peso para existir uma indústria que "resolva" este problema. As indústrias da beleza e da moda, através do seu trabalho de marketing e propaganda, determinam que a "feiura" e a "gordura" são eventos a serem considerados aversivos; aumentando assim o poder de reforço dos produtos e serviços que as removem. As resoluções vendidas pela indústria da beleza não podem ser perfeitas ou duradouras, pois, do contrário, o comportamento da cliente de continuar comprando soluções em estética perderia a função de gerar reforço (lucro) para as ações daqueles que comandam esta indústria. 
Quando o comportamento verbal de qualificar o corpo está sob controle discriminativo das imagens apresentadas na mídia de consumo, em detrimento do próprio corpo como referencial, têm-se um cenário propício para o fenômeno nomeado pela psiquiatria de distorção da categoria IC. Field et al. (1999) realizaram um estudo com 548 estudantes adolescentes norte-americanas do sexo feminino para avaliar a influência da mídia na preocupação com o peso e na percepção do corpo. Inicialmente foi avaliada a intensidade com que as adolescentes tinham contato com revistas de moda através de perguntas como "qual a frequência com que você lê revistas moda ou para adolescentes?"3, "as fotos das mulheres nas revistas fazem você querer perder peso?"; outros tipos de assertivas deveriam ser indicadas como concordo ou não concordo, por exemplo: "Eu iniciei uma dieta para perder peso por causa de um artigo em uma revista". O modelo de regressão logística multivariada apontou que as adolescentes que frequentemente leem revistas de moda apresentaram uma probabilidade de fazer dieta, por causa dos artigos e imagens das revistas, duas vezes maior do que as que não leem frequentemente (OR $=2.11$, IC 95\% = 1.19-3.75). Para o 'fazer atividade física, com a finalidade de perder peso', a probabilidade aumentou em três vezes (OR = 3.02 , IC $95 \%=1.77-5.17)$.

Os modelos estéticos apresentados como ideais e como poderosos meios para obter reforçamento afetivo, social, profissional, financeiro e sexual são frequentemente tão artificiais e estereotipados (pouca variedade de opções) que se tornam difíceis de serem alcançados sem algum tipo de reconstrução do corpo. A indústria do consumo de moda e estética promove ideais de corpos que são inalcançáveis para a maioria dos seres humanos. Por mais que uma adolescente típica tente ter um corpo considerado socialmente perfeito para resolver seus conflitos, ela sempre estará em um padrão abaixo das modelos retocadas digitalmente ou cirurgicamente. A cliente, por mais que perca peso, continuará se avaliando como "gorda" ao se comparar com os corpos da televisão e das revistas. Os sentimentos de fracasso, impotência e desespero caracterizam este momento na vida das clientes. $\mathrm{O}$ mito grego de Sísifo, que tenta cumprir uma tarefa interminável, é uma boa metáfora para descrever a situação das que realizam práticas anoréticas e bulímicas.

Segundo Castilhos (2004) aquelas que não se qualificam esteticamente atraentes podem elaborar estratégias de fuga/esquiva de situações sociais, restringindo as possibilidades de reforçamento social e afetivo. Podem também se engajar no consumo, ou estratégias de restrição alimentar, para mudarem o corpo e assim, talvez, serem aceitas.

Um fenômeno atual dentro da temática dos TA’s são as comunidades da Internet que servem como espaço para promoção das práticas restritivas e purgativas como um estilo de vida glamouroso e inócuo. Nessas comunidades, adolescentes podem se comunicar com pessoas que apresentam interesses em comum, tendo o seu anonimato garantido, esquivando-se assim de potenciais críticas. Existem comunidades específicas voltadas ao tema em vários sites (principalmente blogs e redes sociais) da internet. Elas são chamadas "Pró-Ana" (em prol da anorexia) e "Pró-Mia" (em favor da bulimia). Nos diálogos destas comunidades verbais virtuais são utilizadas gírias que especificam eventos comuns no cotidiano destas adolescentes. Por exemplo: "ana" (anorexia ou anoréxica), "mia" (bulimia) "miar" (vômito induzido), "NF" (abreviação de no food, que significa um ficar sem ingerir comida), "LF" (abreviação de low food, que significa ingerir pouca comida). 
Alguns temas comuns nessas comunidades virtuais são citados a seguir. As frases abaixo foram retiradas de uma comunidade excluída da rede social Orkut devido ao seu conteúdo pró-ana e pró-mia. A identificação ou o contato com as autoras dos relatos não é mais possível (http://www.orkut.com/ Community.aspx? $\mathrm{cmm}=25597445$ - acessado em $30 / 05 / 05$ e 22/04/2006). Os nomes das autoras foram omitidos e o texto foi mantido na íntegra.

1. Trocas de experiências entre usuárias, onde elas ensinam como lidar com as dificuldades na restrição alimentar: "um bom jeito d miar, mas não serve $\mathrm{p} / \log$ o em seguida, então parte da comida jah terah sido absorvida... mas funciona e emagrece, eh tomar água morna d manha. assim q vc acorda, vc toma agua morna (nao natural! morna msm) q dah ânsia! s/ contar q vc fica s/ fome quase o dia td!";

2. Trocas sobre como esconder e ludibriar pais e profissionais de saúde: "Gente minha garganta esta super inflamada e muito, mas muito mesmo dolorida mesmo de tanto miar... Não sei o que eu faço... Dói tanto que eu já não consigo engolir mais nada... Até água me dói!!! Eu não sei o que eu faço... E não quero falar com meus pais pq eu tenho medo de me levarem no médico e o médico descobrir como isso foi causado e contar a eles...O que vcs fazem?";

3. Relatos sobre como iniciaram o quadro: "Bem gente, vou ser breve na minha história! Em +- 8 meses eu perdi 20 kilos, de 65 pra 45, e durante esses meses, eu tive ana por no minimo uns $6 \ldots$ Soh q jah fazem 2 meses q eu tenho mia, e nao paro de engordar, eu tento voltar pra ana mas nao consigo! jah engordei qse 10 kilos! O q q eu faço ?". As depoentes fornecem modelo para as iniciantes nas práticas restritivas.
4. Rede de apoio social: "oi me add no msn.... eu tenho mia faz 3 anos, e sou pro ana, me add q a gente conversa... bjus e não desista nunca!".

As mensagens trocadas entre as usuárias promovem uma valorização social, dentro desta comunidade, para as práticas anoréxicas e bulímicas. Configurando uma contingência de reforço que pode não estar disponível no ciclo de amizades e/ou familiar das clientes. As comunidades na Internet, e pessoas próximas que também realizam as mesmas práticas, acabam sendo as últimas fontes de reforçadores sociais para as práticas restritivas destas adolescentes quando elas perdem peso demais.

Os grupos de mídia que incentivam quem consegue emagrecer atingindo um ideal estético e promovem o culto ao corpo magro, paradoxalmente criticam aquelas que anteriormente tiveram suas práticas restritivas reforçadas e acabaram perdendo peso a ponto de ficar com uma aparência de doente ou mesmo morrer. Diversos programas televisivos apresentam desfiles de moda com modelos muito magras e as tratam como celebridades e referência máxima de beleza. $\mathrm{O}$ mesmo também ocorre em novelas com atrizes magérrimas, que são qualificadas como estrelas e referenciais de beleza e sucesso. Mas os mesmos programas televisivos condenam as práticas restritivas que promovem o emagrecimento destas modelos quando elas morrem de fome, como no caso da morte de alguma modelo ou pessoa comum em decorrência das práticas anoréxicas ${ }^{4}$.

Governos de alguns países já encaram estas práticas culturais promotoras da restrição alimentar como um problema de saúde pública. Na Espanha existe uma proibição para modelos com I.M.C. abaixo de 18 desfilarem. O governo francês e de 
outros países também estudam a implementação de projetos de lei semelhantes (Vlahou, 2006).

\section{Conclusão}

O alimento não se restringe, especialmente nos seres humanos, apenas à manutenção de nossas funções vitais e ao seu valor como reforçador incondicionado. Outras funções de ordem social e ontológica podem caracterizar o alimento enquanto contingência de reforçamento. $\mathrm{O}$ entrelaçamento entre os níveis de seleção não obrigatoriamente é de complementação ou harmonia. O conflito entre eles é uma questão importante na análise clínica das práticas de restrição e purgação. Por conseguinte, o analista do comportamento não deve descartar o entrelaçamento dos três níveis de seleção, tendo especial atenção ao uso da relação com o corpo e com o alimento como forma de lidar com eventos aversivos, considerando que a cultura do consumo estético e as comunidades onde a cliente está inserida (famílias, amigos, redes sociais, etc.) podem propiciar condições favorecedoras para esta situação.

A ocorrência de práticas restritivas e purgativas na população feminina é um problema relevante de saúde pública, exigindo do terapeuta analítico-comportamental conhecimentos específicos sobre a questão. A diversidade de aspectos (econômicos, familiares, políticos, biológicos, etc.) que circunscrevem os quadros de TA demandam uma postura crítica e ampla de análises e intervenções sobre as questões da cliente que está sendo acompanhada, bem como do cenário micro e macro cultural. Outras frentes de atuação, além da clínica, mostram-se necessárias aos analistas do comportamento para lidar com os TA, pois estes são um problema que originam principalmente na forma como certas práticas culturais estão sendo criadas e reproduzidas. Caso uma ação política não seja pensada pela comunidade dos analistas do comportamento, ficarão estes realizando intervenções circunscritas ao modelo clínico clássico da psicologia. A Análise do Comportamento possui aparato teórico, conceitual e de intervenção para planejar e intervir em contextos culturais, na saúde coletiva e políticas públicas. Para tanto, faz-se necessário mais estudos sobre as questões politicas e econômicas que são contingentes aos quadros comportamentais, aqui discutidos, por uma ótica analítico-comportamental.

\section{Referências}

Acuna, K.; Cruz, T. (2004). Avaliação do estado nutricional de adultos e idosos e situação nutricional da população brasileira. Arquivos Brasileiros de Endocrinologia e Metabologia, 48(3), 345- 361.

Aiello, A.L.R. (2002). Identificação precoce de sinais de autismo. In: Guilhardi, et al. (org). Sobre Comportamento e Cognição (v.9), pp.1329. Santo André: Esetec.

Andery, M.A.P.A. (1997). 0 modelo de seleção por consequências e a subjetividade. In: Banaco, R.A. (org.). Sobre Comportamento e Cognição (v.1) pp. 196-205. São Paulo: Arbytes Editora LTDA.

Anjos, L.A. (1992). Índice de massa corporal (massa corporal x estatura2) como indicador do estado nutricional de adultos: revisão da literatura. Revista de Saúde Pública, 26, 431- 436.

Appolinário, J.C. \& Claudino, A.M. (2000). Transtornos Alimentares. Revista Brasileira de Psiquiatia, 22 (supl II), 28-31. 
Appolinário, J.C. (1998) Aspectos biológicos. In: Nunes, M.A.A. et al. Transtornos Alimentares e Obesidade 1ํe edição, pp.57-61. Porto Alegre: Artmed. Araújo, J.R. \& Medeiros, C.A. (2003). Classificação diagnóstica: 0 que a análise do comportamento tem a dizer? In: Sadi, H. M. \& Castro, N. M. S. M.(orgs.). Ciência do comportamento: Conhecer e avançar (v.3), pp.185-94, Santo André : ESETec.

Associação Americana de Psiquiatria (APA). (1995). Manual Diagnóstico e Estatístico de Transtornos Mentais. Porto Alegre: Artes Médicas.

Banaco, R.A. (2001). Técnicas cognitivo-comportamentais e análise funcional. In: Kerbauy, R.R \& Wielenska, R.C. (Orgs.). Sobre comportamento e cognição. Vol. 4, pp. 75-82. Santo André: Arbytes.

Banaco, R.A; Zamignani, D.R \& Meyer, S.B. (2010). Função do Comportamento e do DSM: terapeutas analítico-comportamentais discutem a psicopatologia. In: Tourinho, E.Z. \& Luna, S.V. (Orgs.). Análise do Comportamento: investigações históricas, conceituais e aplicadas. pp.175-191 ed. São Paulo: Roca.

Baum, W.M. (2005). Compreender o behaviorismo: Comportamento, cultura e evolução $2^{a}$ ed. Porto Alegre: Artmed.

Carlson, N.R. (2002). Fisiologia do comportamento $7^{\mathrm{a}}$ ed. Barueri: Manole.

Castilho, S.M. (2004). A imagem corporal. Santo André: Esetec.

Cenci, M; Peres, K.G \& Vasconcelos, F.A.G. (2009). Prevalência de comportamento bulímico e fatores associados em universitárias. Revista de Psiquiatria Clínica, 36(3), 83- 88.

Chiesa, M. (2006). Behaviorismo Radical: A filosofia e a ciência. Brasília: Ibac Editora e Editora Celeiro.

Claudino, A.M; Borges, M.BF. (2002). Critérios diagnósticos para os transtornos alimentares: conceitos em evolução. Revista Brasileira de Psiquiatria, 24(3), 7-12.

Cordás, T.A. (1993). Quando o Medo de Ficar Gordo Vira Doença: Anorexia e Bulimia. In: Cordás, T.A., et al. Fome de Cão (pp.17-28). São Paulo: Editora Maltese.

Cordás, T.A. (1995). Avaliação da eficácia terapêutica de dois modelos de atendimento em bulimia nervosa. Tese de doutorado, Faculdade de Medicina da Universidade de São Paulo, São Paulo (SP).

Cordás, T.A., et al. (1998). Anorexia e Bulimia: 0 que são? Como ajudar? Porto Alegre: Artes Médicas.

Deaver, CM; Miltenberger, RG; Smyth, J; Meidinger, A \& Crosby, R. (2003). An evaluation of affect and binge eating. Behavior Modification 27, 578-599.

Delitti, M. (2001). Análise funcional: o comportamento do cliente como foco da análise funcional. In: Delitti, M. (org.). Sobre comportamento e cognição: A prática da análise do comportamento e terapia cognitivo-comportamental (v.2), pp. 35-42. Santo André: Esetec.

Delitti, M. (2005) A relação terapêutica na terapia comportamental. In: Guilhardi, H.J., Aguirre, N.C. (orgs). Sobre comportamento e cogniçã̃: Expondo a variabilidade (v.15), pp.360- 369. Santo André: Esetec.

Fiates, GMR \& Salles, RK. (2001). Fatores de risco para o desenvolvimento de distúrbios alimentares: um estudo em universitárias. Revista de Nutrição, 14, 3-6.

Field, A.E., Cheung, L., Wolf, A.M., Herzog, D.B., Gortmaker, D.B., Coldtiz, G.A. (1999). Exposure to the mass media and weight concerns among girls. Pediatrics, 103(3), 1-5.

Fleitlich, B.W. (1997). 0 papel da imagem corporal e o risco de transtornos alimentares. Pediatria Moderna, 32 (1/2), 56-62.

Fortes, M. (2006). Atividade física no tratamento da obesidade. In: Nunes, M.A., Appolinario, J.C., Galvão, A.L. et al. Transtornos alimentares e obesidade $2^{\mathfrak{a}}$ edição, pp.299-313. Porto Alegre: Artmed. 
Garner, D.M.; Garfinkel, P.E. (1980) Socio-cultural factors in the development of anorexia nervosa. Psychological Medicine, 10, 647- 656.

Goldbloom, D.S. \& Garfinkel, P.E. (1992) Transtornos Alimentares: Anorexia Nervosa e Bulimia Nervosa. In: Garfinkel, P.E. \& Carlson, W. Transtornos Psiquiátricos na Infância e Adolescência. Porto Alegre: Artes Médicas.

Green, L. \& Freed, D.E. (1993). The substitutability of reinforcers. Journal of the Experimental Analysis of Behavior, 60, 141-158.

Guilhardi, H.J. (2002). A Resistência do Cliente a Mudanças. In: Guilhardi et al. Sobre Comportamento e Cognição (v.9), pp.133-156, Santo André: Esetec.

Heatherton, T. F. \& Baumeister, R. F. (1991). Binge eating as escape from self-awareness. Psychological Bulletin. 110(1):86-108.

Heller, D.C.L. (2002). Anorexia nervosa: etiologia e estratégias de enfrentamento. In: Guilhardi, H.J. et al (org.). Sobre comportamento e cognição: Contribuições para a construção da teoria do comportamento (v.10), pp.61-68, Santo André: Esetec.

Jimerson, C.D.; Lesem, M.D et al. (1992). Low serotonin and dopamine metabolite concentrations in cerebrospinal fluid from bulimic patients with frequent binge episodes. Arquives of General Psychiatry, 9(2), 132- 138.

Kaplan, H.I.; Sadock, B.J. \& Grebb, J.A. (1997). Compêndio de Psiquiatria 7a edição. Porto Alegre: Artes Médicas.

Kuppferman, I., Schwartz, J. (1995). Motivation. In: Kandel, E. R; Schwartz, J.H.; Jessel, T.M. Essentials of neural science and behavior (pp.613-627). Londres: Prentice Hall.

Meyer, S.B. (2003). Análise funcional do comportamento. In: Costa, C.E. et al. Primeiros passos em análise do comportamento e cognição (v.1). pp. 75-91. Santo André: Esetec.

Meyer, Sonia Beatriz. (2008). Functional Analysis of Eating Disorders. Journal of Behavior Analysis in Health, Sports, Fitness and Medicine, 1(1), 26-33.

Millenson, J.R. (1967). Princípios de análise do comportamento. Brasília: Thesaurus.

Morgan, C.M; Vecchiatti, I.R. \& Negrão, A.B. (2002). Etiologia dos transtornos alimentares: aspectos biológicos, psicológicos e sócio-culturais. Revista Brasileira de Psiquiatria, 24(3), 18-23.

Moschetta, G.H. \& Cordioli, A.V. (1985). Anorexia Nervosa: uma discussão etiológica. Revista do Hospital das Clínicas de Porto Alegre, 5 (2), 111- 115.

Netto, Carlos A. (2002). Psicobiologia do comportamento alimentar. In: Nunes, M. A., Appolinário, J. C. et. al. Transtornos Alimentares e Obesidade (pp.47-53), Porto Alegre: Artmed.

Nunes, M.A., Appolinário, J.C. et al (1998). Transtornos Alimentares e Obesidade. (1ª edição). Porto Alegre: Artmed.

Organização Mundial de Saúde (OMS). (1993) Classificação de Transtornos Mentais e de Comportamento da CID-10. Porto Alegre: Artes Médicas.

Organização Pan-Americana da Saúde (OPAS). Doenças crônico-degenerativas e obesidade: estratégia mundial sobre alimentação saudável, atividade física e saúde. Brasília: OPAS; 2003.

Paxton, S. J. \& Diggens, J. (1997), Avoidance coping, binge eating, and depression: An examination of the escape theory of binge eating. International Journal of Eating Disorders, 22(1), 83 - 87.

Paxton, S.J. (1998). Current issues in eating disorders research. Journal of Psychosomatic Research, 44(34), 297- 299.

Ribeiro, P.G., Silva, E.P., Costa, G., Heller, D.C.L. (2006). Imagem corporal e transtornos alimentares. In: Guilhardi, H.J., Aguirre, N.C. (orgs). Sobre comportamento e cognição: Expondo a variabilidade (v.18). pp 325-330. Santo André: Esetec.

Routtenberg, A. (1968). "Self-starvation" of rats living in activity wheels: Adaptation effects. Journal of Comparative Psychology, 66,234-238. 
Sampaio, P. (2006). Anoréxica, modelo morre aos 21 com 40kg. Folha de São Paulo. Recuperado em 14 novembro, 2006, de http://www1. folha.uol.com.br/folha/cotidiano/ult95u128220.shtml.

Scoz, M.C.P. (2001). Conhecer o outro: uma análise crítica do conceito de diagnóstico psicológico a partir do behaviorismo radical de B. F. Skinner. Dissertação (Mestrado em Psicologia Experimental) Programa de estudos pós-graduados, Pontifícia Universidade Católica de São Paulo. São Paulo (SP).

Skinner, B. F. (1953). Science and human behavior. New York: McMillan.

Skinner, B.F. (1974). About behaviorism. New York: Alfred A. Knopf.

Skinner, B.F. (1981). Selection by consequences. Science, 213 (4507), 501- 504.

Starling, R.R. (2000). A interface comportamento/neurofisiologia numa perspectiva behaviorista radical: o relógio causa as horas? In: Kerbauy, R.R. et al (Org.). Sobre comportamento e cognição: da reflexão teórica à diversidade da aplicação. v.5, pp. 1-13.Santo André: Esetec.

Stice E, Schupak-Neuberg E, Shaw H.E. \& Stein R.I. (1994). Relation of media exposure to eating disorder symptomatology: An examination of mediating mechanisms. Journal of Abnormal Psychology, 103(4), 836-840.

Vale, A.M.O. (2002). Comportamento alimentar anormal e práticas inadequadas para controle de peso entre adolescentes do sexo feminino de Fortaleza. Dissertação de Mestrado, Programa de Pós-Graduação em Saúde Pública, Universidade Federal do Ceará, Fortaleza (CE).

Vermes, J.S. \& Zamignani, D.R. (2002). A perspectiva analítico-comportamental no manejo do comportamento obsessivo-compulsivo: estratégias em desenvolvimento. Revista Brasileira de Terapia Comportamental e Cognitiva. 4(2): 135-149.

Vlahou, A. (2006). Morte de brasileiras reacende debate na Itália sobre anorexia. Folha de São Paulo. Recuperado em 21 novembro, 2006, de http://www1.folha.uol.com.br/folha/cotidiano/ult95u128220.shtml.

Wurtman, R. J. (1987). Nutrients affecting brain composition and behavior. Integrative Psychiatry, 5, 226-257.

Zamignani, D.R. (2000). Uma tentativa de entendimento do Comportamento obsessive-compulsivo: algumas variáveis negligenciadas. In: Wielenska, R.C. (Org.). Sobre comportamento e cognição: questionando e ampliando a teoria e as intervenções clínicas e em outros contextos. (pp.256-66). Santo André: Esetec.

Zamignani, D.R. \& Banaco, R.A. (2005). Um panorama analítico-comportamental sobre os transtornos de ansiedade. Revista Brasileira de Terapia Comportamental e Cognitiva. 2(1): 77- 92.

\section{NOTAS}

1- Broberg, D. J.; Bernstein, I.L. (1989) Cephalic insulin release in anorexic women. Psysiology and Behavior. 45:871-874.

2- Referente ao Photoshop - software utilizado em propagandas para modificar digitalmente as imagens.

3- No original em inglês a pergunta era "How often do you read magazines (for example, seventeen, Jet, Sassy, Glamour...)?"

4- Ver http://www1.folha.uol.com.br/folha/cotidiano/ult95u128220.shtml como exemplo (Sampaio, 2006). 